\title{
THE PROTON FORMATION FROM METHANE BY DISSOCIATIVE IONIZATION IN THE ELECTRON ENERGY RANGE OF 25-40 eV
}

\author{
R. LOCHT and J. MOMIGNY \\ Institut de Chimie, Département de Chimie Générale et Chimie Physique, Université de Liège, Sart-Tilman, B- \\ 4000 Liège I, Belgium
}

\begin{abstract}
The proton formation by dissociative electroionization of methane has been investigated in the energy range of 25-40 eV. The kinetic energy-versus-appearance energy shows five different $\mathrm{H}^{+}$producing processes respectively at $26.3 \pm 0.2 \mathrm{eV}, 26.9 \pm 0.2 \mathrm{eV}, 29.4 \pm 0.3 \mathrm{eV}, 32.7 \pm 0.2 \mathrm{eV}$ and $35.7 \pm 0.5 \mathrm{eV}$. These critical energies are discussed in terms of different dissociation channels probably opened through predissociation of doubly excited states of $\mathrm{CH}_{4}^{+}$. On the high energy side of the electron energy range investigated in the present work, the proton would appear through the dissociation of the $\mathrm{CH}^{+}$ion as an intermediate.
\end{abstract}

\section{Introduction}

In a recent paper [1] we published the results obtained for the first two processes producing protons and deuterons from methane and methane- $d_{4}$ under the impact of low energy electrons in the range of $20-23 \mathrm{eV}$. The comparison of our data with previous work on the dissociative ionization as well as the dissociative excitation of methane by electron and photon impact was extensively discussed. The appearance mechanisms involving thermal and $2.3 \mathrm{eV}$ kinetic energy protons were both related to dissociative autoionization. The strong parallelism between the results obtained either by electroionization or by dissociative excitation were discussed.

The present paper is concerned with the investigation of the proton formation at higher electron energies, i.e. in the range of 25-40 eV. In this energy range the most detailed dissociative electroionization work so far has been published by Appell [2]. Both kinetic energy and appearance energy of the protons have been measured. Concerning the existence of electronically excited states of $\mathrm{CH}_{4}^{+}$in the energy range of interest, Backx et al. [3] and van der Wiel et al. [4], using electron energy loss spectroscopy of high-energy primary electrons and $(\mathrm{e}, 2 \mathrm{e})$ experiment, found two "photoelectron bands" corresponding to two doubly excited states of $\mathrm{CH}_{4}^{+}$.

\section{Experimental results}

The operating conditions maintained in the course of this work are identical with those described in ref. [1]. An electronical improvement of the detection system enabled to increase the sensitivity for the onset energy measurements of highly energetic protons.

Figs. 1 and 2, respectively, show the kinetic energy distribution of $\mathrm{H}^{+} / \mathrm{CH}_{4}$ obtained with $50 \mathrm{eV}$ electrons and the ionization efficiency curve of the proton for the retarding potential setting $V_{R}=0 \mathrm{~V}$.

Fig. 3 shows the final result obtained by recording the ionization efficiency curve of $\mathrm{H}^{+}$at retarding potential settings increased by $0.2 \mathrm{~V}$ between $0-5.0 \mathrm{~V}$. Each data point thus obtained is the averaged value of at least five independent measurements. The error bars measure the largest deviation from the mean value. For higher retarding potentials, i.e. over $5.0 \mathrm{~V}$, the signal is of too low intensity to allow valuable onset energy measurements. The processes numbered by (1) and (2) being extensively discussed in ref. [1], only the diagram portions (3)-(7) will be discussed in the following sections. 
Fig. 1. Energy distribution of the protons from $\mathrm{CH}_{4}$ obtained with $50 \mathrm{eV}$ electrons. Maxima measured at $0.0 \mathrm{eV}$, $0.5 \mathrm{eV}, 0.9 \mathrm{eV}, 2.3 \mathrm{eV}$ and $3.9 \mathrm{eV}$ (ref. [1]).

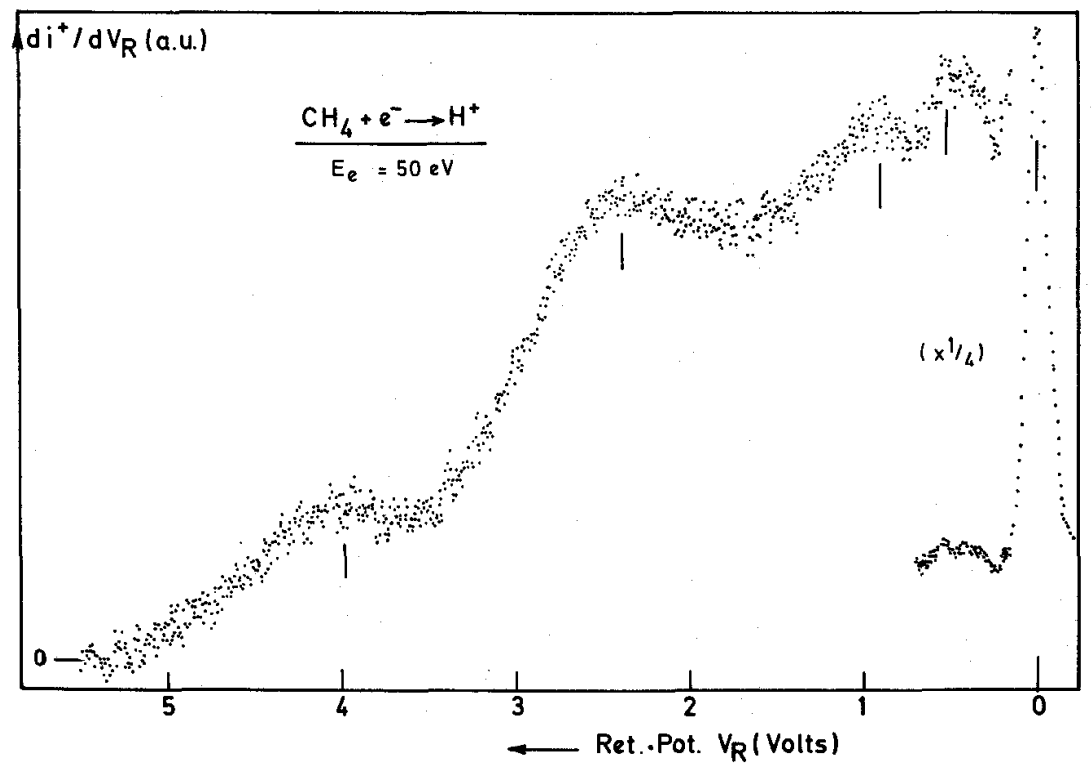

Fig. 2. First $\left(d i^{+} / d E_{e}\right)$ and second $\left(d^{2} i^{+} / d E_{e}{ }^{2}\right)$ derivatives of the electroionization efficiency curve of $\mathrm{H}^{+} / \mathrm{CH}_{4}$ obtained for $V_{R}=0 \mathrm{~V}$. Threshold energies at $21.3 \mathrm{eV}, 22.2 \mathrm{eV}, 26.8 \mathrm{eV}$ and $29.4 \mathrm{eV}$ (ref. [1]).

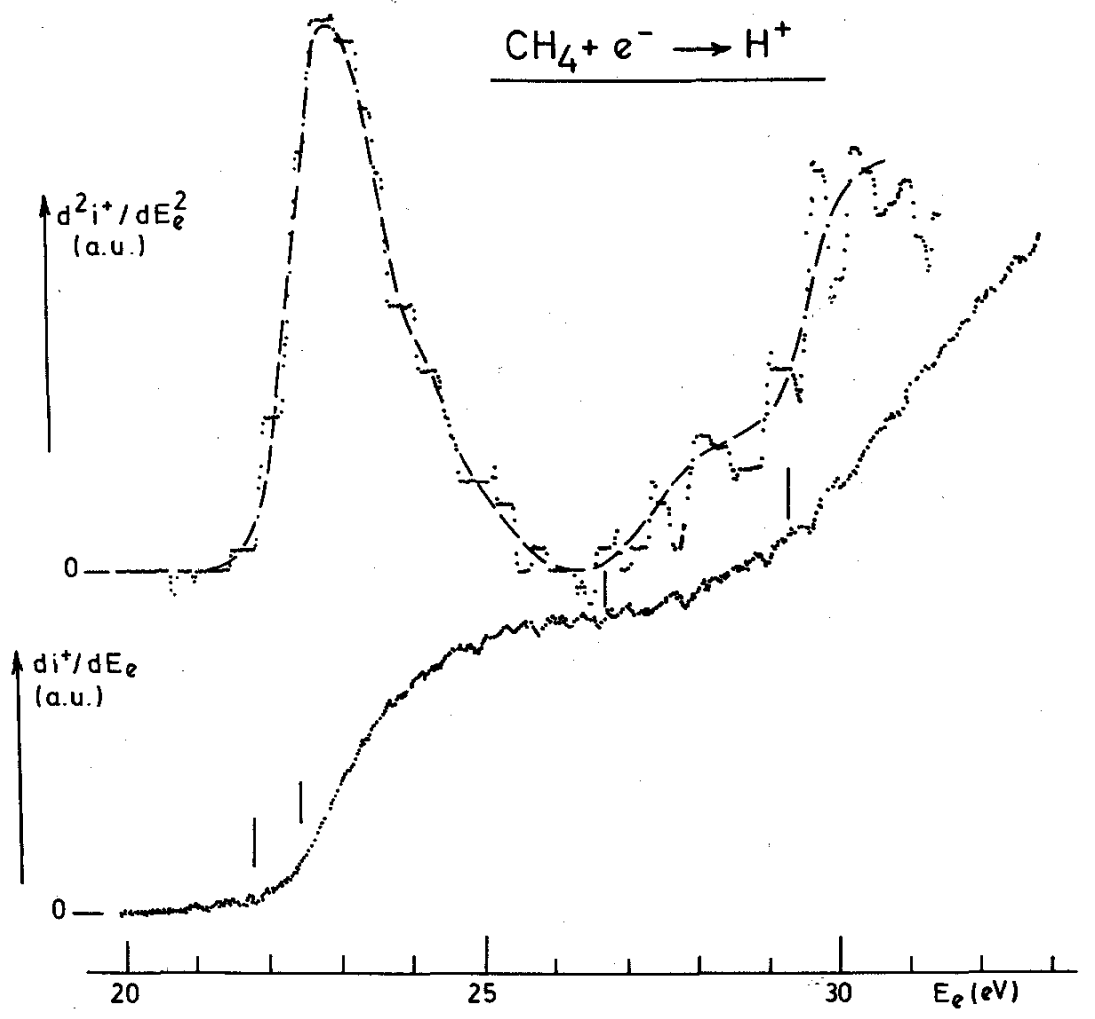


Fig. 3. Kinetic energy (KE)-versus-appearance energy (AP) plot for $\mathrm{H}^{+} / \mathrm{CH}_{4}$. For diagram portion numbering, see text.

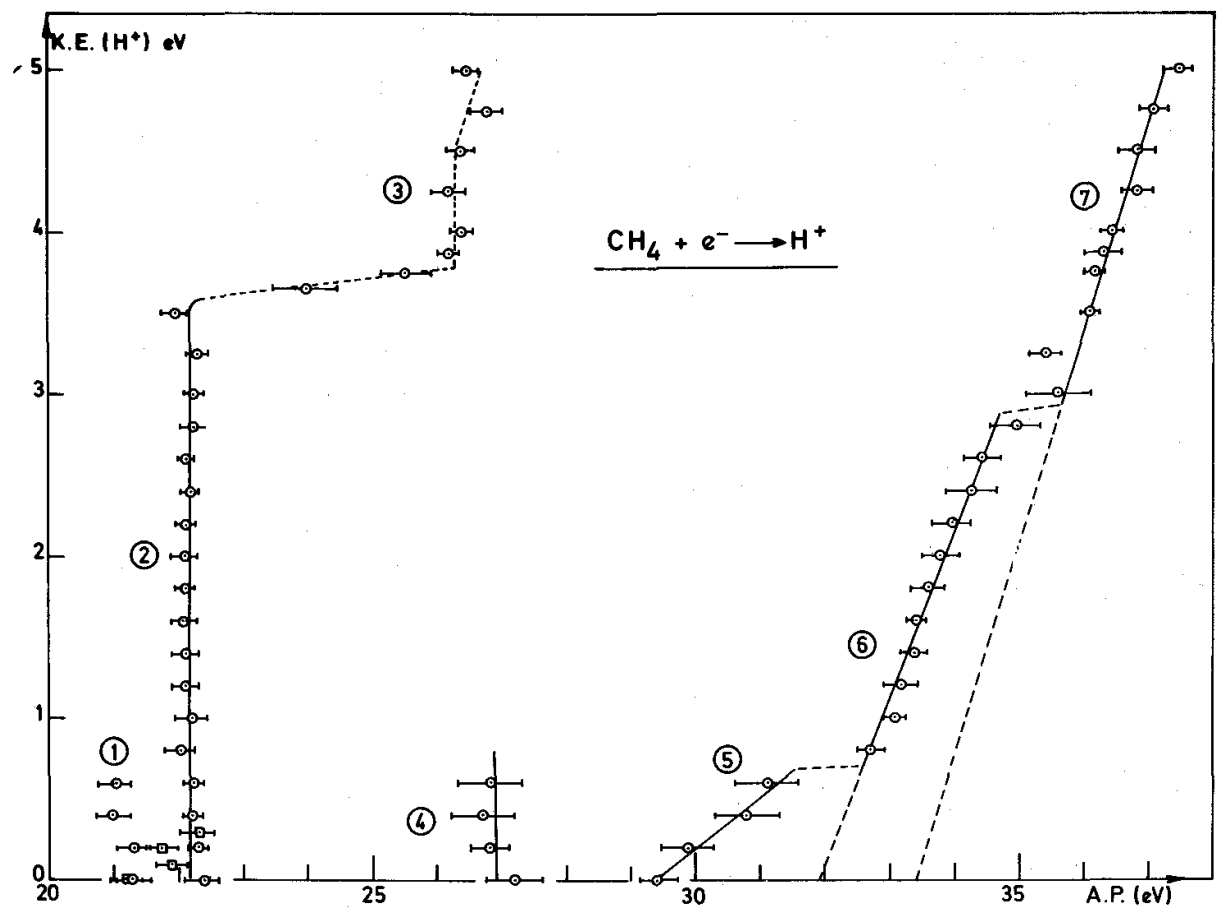

\section{Discussion}

In the energy range of interest, the data obtained in earlier dissociative electroionization and dissociative excitation work have been gathered in table 1 and the dissociation limits which could be involved in the same energy range are listed in table 2. For the sake of clarity each diagram portion (3)-(7) will be discussed separately.

Table 1 Comparison of experimental results with previous studies. Onset energies (eV) and corresponding kinetic energy range in parentheses $(\mathrm{eV})$

\begin{tabular}{lllll}
\hline & Appell [2] & Schiavone [5] & Finn [6] & Present work \\
\hline process (3) & $28(4.7)$ & $24.5 \pm 0.5(4.7-8.4)$ & $25.5 \pm 0.6(<7.5)$ & $26.3 \pm 0.2(4.0)$ \\
process (4) & $26.5(0-1.2)$ & $26.4 \pm 0.5(0.3-2.6)$ & - & $26.9 \pm 0.2(0-0.6)$ \\
process (5) & $31.0(3-4.7)$ & - & - & $29.4 \pm 0.3(0-0.6)$ \\
process (6) & - & - & - & $32.7 \pm 0.2(0.6-2.8)$ \\
process (7) & $33.0(3-4.7)$ & $34.8 \pm 0.5(3-15)$ & $36.7 \pm 0.6(>3.2)$ & $35.7 \pm 0.5(3.0-5.0)$ \\
\hline
\end{tabular}

\subsection{Process (3)}

The vertical portion of process (3) is measured at an average value of $26.3 \pm 0.2 \mathrm{eV}$ (see fig. 3). Between processes (2) and (3) a sudden and step-like change in appearance energy is observed. Both processes are separated by $\Delta(\mathrm{AP})=4.2 \pm 0.3 \mathrm{eV}$ for a variation of about $0.2 \mathrm{eV}$ kinetic energy. With a monoenergetic electron beam and a better kinetic energy resolution, the broken line between processes (2) and (3) would tend to be parallel to the AP-axis. This feature in the diagram indicates that the energy of $4.2 \mathrm{eV}$ is entirely converted into internal energy of the fragments. 


\begin{tabular}{|c|c|c|}
\hline Dissociation products & & $\begin{array}{c}\text { Energy } \\
(\mathrm{eV})\end{array}$ \\
\hline \multicolumn{3}{|l|}{$\overline{\mathrm{CH}_{4}+\mathrm{e} \sim}$} \\
\hline$\rightarrow \mathrm{H}^{+}+\mathrm{CH}_{3}\left(\widetilde{\mathrm{B}}^{2} \mathrm{~A}_{1}^{\prime}\right)+2 \mathrm{e}^{-}$ & $(1)$ & 23.78 \\
\hline$\left(\widetilde{\mathrm{C}}^{2} \mathrm{E} "\right)$ & $(2)$ & 26.30 \\
\hline$\left(\widetilde{D}^{2} \mathrm{~A}_{1}^{\prime}\right)$ & (3) & 26.33 \\
\hline$\rightarrow \mathrm{H}^{+}+\mathrm{H}+\mathrm{CH}_{2}\left(\mathrm{X}^{3} \mathrm{~B}_{1}\right)+2 \mathrm{e}^{-}$ & (4) & 22.95 \\
\hline$\left({ }^{1} B_{1}\right)$ & $(5)$ & 24.75 \\
\hline$\left({ }^{1} \mathrm{~A}_{1}^{\prime}\right)$ & $(6)$ & 27.35 \\
\hline$\rightarrow \mathrm{H}^{+}+\mathrm{H}_{2}+\mathrm{CH}\left(\mathrm{X}^{2} \Pi\right)+2 \mathrm{e}^{-}$ & (7) & 22.85 \\
\hline$\left(\mathrm{A}^{2} \Delta\right)$ & $(8)$ & 25.70 \\
\hline$\left(\mathrm{B}^{2} \Sigma^{-}\right)$ & (9) & 26.08 \\
\hline$\left(C^{2} \Sigma^{+}\right)$ & $(10)$ & 26.79 \\
\hline$\rightarrow \mathrm{H}^{+}+2 \mathrm{H}+\mathrm{CH}\left(\mathrm{X}^{2} \Pi\right)+2 \mathrm{e}^{-}$ & (11) & 27.32 \\
\hline$\left(\mathrm{A}^{2} \Delta\right)$ & (12) & 30.17 \\
\hline$\left(\mathrm{B}^{2} \Sigma^{-}\right)$ & (13) & 30.55 \\
\hline$\left(C^{2} \Sigma^{+}\right)$ & (14) & 31.26 \\
\hline$\left.\rightarrow \mathrm{H}^{+}+\mathrm{H}_{2}+\mathrm{H}+\mathrm{C}^{3}{ }^{3} \mathrm{P}\right)+2 \mathrm{e}^{-}$ & $(15)$ & 26.28 \\
\hline$\left({ }^{1} \mathrm{D}\right)$ & (16) & 27.54 \\
\hline$\left({ }^{1} \mathrm{~S}\right)$ & (17) & 28.96 \\
\hline$\left.\rightarrow \mathrm{H}^{+}+3 \mathrm{H}+\mathrm{C}^{3} \mathrm{P}\right)+2 \mathrm{e}^{-}$ & (18) & 30.75 \\
\hline$\left({ }^{1} \mathrm{D}\right)$ & (19) & 32.01 \\
\hline$\left({ }^{1} \mathrm{~S}\right)$ & $(20)$ & 33.43 \\
\hline$\rightarrow \mathrm{H}^{+}+\mathrm{CH}_{3}^{+}\left(\mathrm{X}^{1} \mathrm{~A}_{1}^{\prime}\right)+3 \mathrm{e}^{-}$ & $(21)$ & $27.89^{\text {a) }}$ \\
\hline$\left({ }^{3} E^{\prime \prime}\right)$ & $(22)$ & $32.81^{\text {a) }}$ \\
\hline$\left({ }^{1} E^{\prime \prime}\right)$ & $(23)$ & $34.15^{\text {a) }}$ \\
\hline$\rightarrow \mathrm{H}++\mathrm{H}+\mathrm{CH}_{2}^{+}\left(\widetilde{\mathrm{X}}^{2} \mathrm{~A}_{1}\right)+3 \mathrm{e}^{-}$ & (24) & 33.35 \\
\hline$\rightarrow \mathrm{H}^{+}+\mathrm{H}^{+}+\mathrm{CH}_{2}\left(\widetilde{\mathrm{X}}^{3} \mathrm{~B}_{1}\right)+3 \mathrm{e}^{-}$ & $(25)$ & 36.55 \\
\hline$\rightarrow \mathrm{H}^{+}+\mathrm{H}_{2}+\mathrm{CH}^{+}\left(\mathrm{X}^{1} \Sigma^{+}\right)+3 \mathrm{e}^{-}$ & (26) & 33.49 \\
\hline$\left(\mathrm{A}^{1} \Pi\right)$ & (27) & 36.41 \\
\hline$\left({ }^{1} \Delta\right)$ & $(28)$ & 37.03 \\
\hline
\end{tabular}

Table 2 Thermochemically calculated dissociation limits leading to proton formation from methane in the energy range of 23-37 eV. Dissociation energies are taken from ref. [8], ionization and excitation energies of atoms from ref. [9], ionization and excitation energies of diatomic and poly-atomic radicals from refs. [10] and [11], respectively

Appell [2] observed the same jump of about $4.0 \mathrm{eV}$ for the threshold energy in the interval of $24-28 \mathrm{eV}$. This author measured onset energies for protons carrying up to $7 \mathrm{eV}$ total kinetic energy, and above $4.7 \mathrm{eV}$ the translational energy is linearly dependent upon the electron energy in the range of 28-30 eV. By extrapolation to zero kinetic energy, Appell [2] obtained a dissociation limit of $23.1 \pm 0.5 \mathrm{eV}$ and ascribed the production of these ions to the processes

$$
\begin{aligned}
\mathrm{CH}_{4}+\mathrm{e}^{-} & \rightarrow \mathrm{H}^{+}+\mathrm{CH}_{3}\left(\widetilde{\mathrm{B}}^{2} \mathrm{~A}_{1}^{\prime}\right)+2 \mathrm{e}^{-} \\
& \rightarrow \mathrm{H}^{+}+\mathrm{H}+\mathrm{CH}_{2}\left(\widetilde{\mathrm{X}}^{3} \mathrm{~B}_{1}\right)+2 \mathrm{e}^{-} \\
& \rightarrow \mathrm{H}^{+}+\mathrm{H}_{2}\left(\mathrm{X}^{1} \Sigma_{\mathrm{g}}^{+}\right)+\mathrm{CH}\left(\mathrm{X}^{2} \Pi\right)+2 \mathrm{e}^{-},
\end{aligned}
$$

calculated as lying respectively at 23.78 $\mathrm{eV}, 22.95 \mathrm{eV}$ and $22.85 \mathrm{eV}$. The difference in onset energy, i.e. $28 \mathrm{eV}$ in ref. [2] and $26.3 \mathrm{eV}$ measured in the present work, is unexplained.

Schiavone et al. [5] and Finn et al. [6] measured an onset energy of $24.5 \pm 0.5 \mathrm{eV}$ and $25.5 \pm 0.5 \mathrm{eV}$ for high-Rydberg $\mathrm{H}^{*}$ atoms from $\mathrm{CH}_{4}$ carrying 4.7-8.4 eV kinetic energy. Oertel [7] measured the second onset for Lyman $\alpha, \beta$ and $\gamma$ emission from $\mathrm{H}^{*} / \mathrm{CH}_{4}$ at $25.3 \pm 1.2 \mathrm{eV}, 25.8 \pm 1.2 \mathrm{eVand} 25.8 \pm 1.2 \mathrm{eV}$. None of these authors give an interpretation of the processes observed between $24.5-25.8 \mathrm{eV}$.

Van der Wiel et al. [4] obtained an (e, 2e) spectrum with high-energy primary electrons on $\mathrm{CH}_{4}$. A first "band" having its adiabatic ionization energy near $26 \mathrm{eV}$ and the vertical ionization energy at about $28 \mathrm{eV}$, is ascribed to the simultaneous ionization and excitation of the $\mathrm{CH}_{4}$ molecule. Appell [2] and Backx et al. [3] proposed the $\left(1 \mathrm{t}_{2}\right)^{-2}\left(3 \mathrm{a}_{1}\right)^{1}$ configuration for the $\mathrm{CH}_{4}^{+}$molecular ion. This configuration gives rise to a manifold of electronic states, i.e. ${ }^{4} \mathrm{~F}_{1},{ }^{2} \mathrm{~A}_{1},{ }^{2} \mathrm{E},{ }^{2} \mathrm{~F}_{1}$ and ${ }^{2} \mathrm{~F}_{2}$ in the tetrahedral symmetry $\mathrm{T}_{\mathrm{d}}[11]$.

Process (2) (see fig. 3) having its onset at $22.2 \mathrm{eV}$ [1] has been ascribed to the protons producing mechanism [1]

$$
\begin{aligned}
\mathrm{CH}_{4}+\mathrm{e}^{-} \rightarrow \mathrm{CH}_{4}^{*}+\mathrm{e}^{-} & \\
& \stackrel{\rightarrow}{\rightarrow} \mathrm{CH}_{3_{\mathrm{v}}}+\mathrm{H}^{+}+\mathrm{e}^{-},
\end{aligned}
$$

where the vibrationally excited radical $\mathrm{CH}_{3 \mathbf{v}}$ is formed by the dissociative autoionization of a superexcited $\mathrm{CH}_{4}{ }^{*}$ state and carries translational and internal energy. The lowest dissociation limit for this process is calculated at $18.1 \mathrm{eV}$ and the maximum total translational energy measured on $\mathrm{H}^{+}$is of $3.5 \mathrm{eV}$. The internal energy carried by 
$\mathrm{CH}_{3}$ is $0.6 \mathrm{eV}$. The $4.2 \pm 0.3 \mathrm{eV}$ energy difference between processes (2) and (3) is entirely converted into internal energy (see fig. 3).

A first interpretation of the proton formation at $26.3 \mathrm{eV}$ would be that the total internal energy, i.e. $4.8 \pm$ $0.3 \mathrm{eV}$, is stored in the $\mathrm{CH}_{3}$ radical. This quantity has to be compared with the value of the dissociation energy $D\left(\mathrm{CH}_{2}-\mathrm{H}\right)=4.9 \mathrm{eV}$ [8]. The minimum observed kinetic energy involved in this process is $4.1 \pm 0.2 \mathrm{eV}$. The tail rising up from 4.2-5.0 eV kinetic energy indicates the occurrence of the same process where the proton carries an increasing amount of translational energy. However, the accuracy of the present measurements does not allow us to determine the slope of the straight line fitting the data between 4.5-5.0 eV. The slope of about 1.0 drawn in fig. 3 would lie on the assumption that $\mathrm{H}^{+}$only carries the total excess translational energy. In this case a twostep mechanism would give rise to protons, i.e.

$$
\begin{aligned}
& \mathrm{CH}_{4}+\mathrm{e}^{-} \rightarrow \mathrm{CH}_{3}^{*}+\mathrm{H}^{+}+2 \mathrm{e}^{-} \\
& \left\llcorner\mathrm{CH}_{2}\left(\widetilde{\mathrm{X}}^{3} \mathrm{~B}_{1}\right)+\mathrm{H}\right. \text {, }
\end{aligned}
$$

where step (b) is kinetically slower than step (a). Such a mechanism could take place through predissociation of the first doubly excited state of $\mathrm{CH}_{4}^{+}$corresponding to the configuration $\left(1 \mathrm{t}_{2}\right)^{-2}\left(3 \mathrm{a}_{1}\right)^{1}$ with an adiabatic ionization energy of about $26 \mathrm{eV}$ [4]. This state, probably the ${ }^{4} \mathrm{~F}_{1}$ state, is correlated with a ${ }^{4} \mathrm{~A}^{\prime}$ in the $\mathrm{C}_{\mathrm{s}}$ symmetry [11] for which the energy has been calculated by Leclerc and Guissard-Galloy [14]. This could lead to the dissociation limit $\mathrm{CH}_{2}\left(\widetilde{\mathrm{X}}{ }^{3} \mathrm{~B}_{1}\right)+\mathrm{H}+\mathrm{H}^{+}$as schematically shown in fig. 4. These products would give rise to ${ }^{2} \mathrm{~A}^{\prime \prime}$ and ${ }^{4} \mathrm{~A}^{\prime \prime}$ states which would predissociate the ${ }^{4} \mathrm{~A}^{\prime}$ state of $\mathrm{CH}_{4}$. Accounting for the error on the measurements, a lower limit of 0.5 for a slope could be estimated and would account for a straight dissociation of $\mathrm{CH}_{4}^{+}$by

$$
\mathrm{CH}_{4}+\mathrm{e}^{-} \rightarrow \mathrm{CH}_{2}\left(\widetilde{\mathrm{X}}^{3} \mathrm{~B}_{1}\right)+\mathrm{H}+\mathrm{H}^{+}+2 \mathrm{e}^{-}
$$

An alternative dissociation path, having its thermochemical threshold at about the same energy, would be process (7) in table 2. The same two-step mechanism could be involved.

$$
\begin{aligned}
& \mathrm{CH}_{4}+\mathrm{e}^{-} \rightarrow \mathrm{CH}_{3}^{*}+\mathrm{H}^{+}+2 \mathrm{e}^{-} \\
& \rightarrow \mathrm{CH}\left(\mathrm{X}^{2} \mathrm{II}\right)+\mathrm{H}_{2} .
\end{aligned}
$$

\subsection{Process (4)}

The vertical line in fig. 3 at $26.9 \pm 0.2 \mathrm{eV}$ corresponds to the threshold of a process observed in the kinetic energy range of $0-0.6 \mathrm{eV}$. Being very difficult to observe, the onset of this process could not be measured for higher values of the translational energy (see fig. 5 in ref. [1]).

As shown in fig. 5, a suddenly rising contribution of low energy protons is observed when the kinetic energy distribution of $\mathrm{H}^{+} / \mathrm{CH}_{4}$ is recorded at $25 \mathrm{eV}$ and $30 \mathrm{eV}$. This noticeable change when the electron energy rises from 25 to $30 \mathrm{eV}$, indicates that the proton energy distribution corresponding to process (4) is probably given by the maximum observed at $0.5 \mathrm{eV}$ (see figs. 1 and 5).

The present onset energy measurement has to be compared with the threshold measured by Appell [2] at $26.5 \mathrm{eV}$ for low-energy protons and by Schiavone et al. [5] at $26.4 \pm 0.5 \mathrm{eV}$ for low-energy high-Rydberg $\mathrm{H}^{*}$ atoms. The latter authors observed a linear dependence of the kinetic energy with respect to the onset energy and suggested that the ionic dissociation limit would involve the $\mathrm{CH}_{3}$ radical excited in the $\widetilde{\mathrm{C}}{ }^{2} \mathrm{E}^{\prime \prime}$ or $\widetilde{\mathrm{D}}^{2} \mathrm{~A}_{1}^{\prime}$ state [processes (2) and (3) in table 2]. However, as mentioned by Appell [2] many other dissociation channels are energetically open in the energy range of $26-27 \mathrm{eV}$ (see table 2). One of these, leading to $\mathrm{H}^{+}+\mathrm{H}+\mathrm{H}_{2}\left({ }^{1} \Sigma_{\mathrm{g}}{ }^{+}\right)+$ $\mathrm{C}\left({ }^{3} \mathrm{P}\right)$, is represented schematically in fig. 4 . 
Fig. 4. Correlation diagram between $\mathrm{CH}_{4}{ }^{+}$and its dissociation products in the energy range of $26 \mathrm{eV}$. For the discussion, see text.

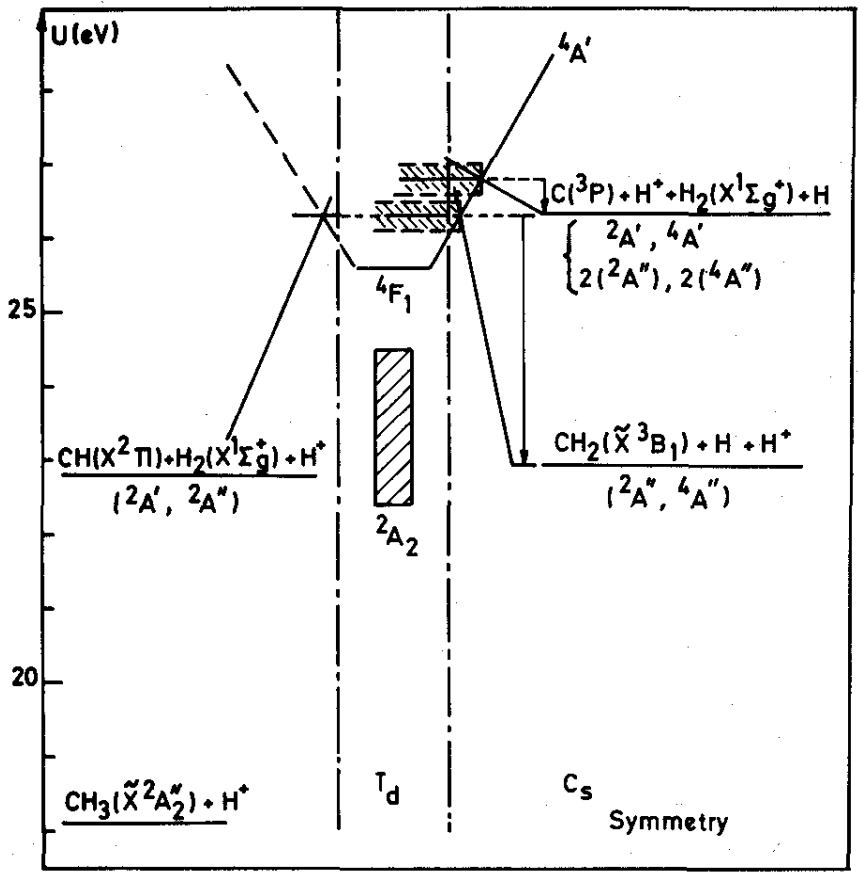

Fig. 5. Kinetic energy distribution of $\mathrm{H}^{+} / \mathrm{CH}_{4}$ obtained with $30 \mathrm{eV}$ (1) and $25 \mathrm{eV}$ (2) electrons. Note the intensity increase of low energy ions at $30 \mathrm{eV}$.

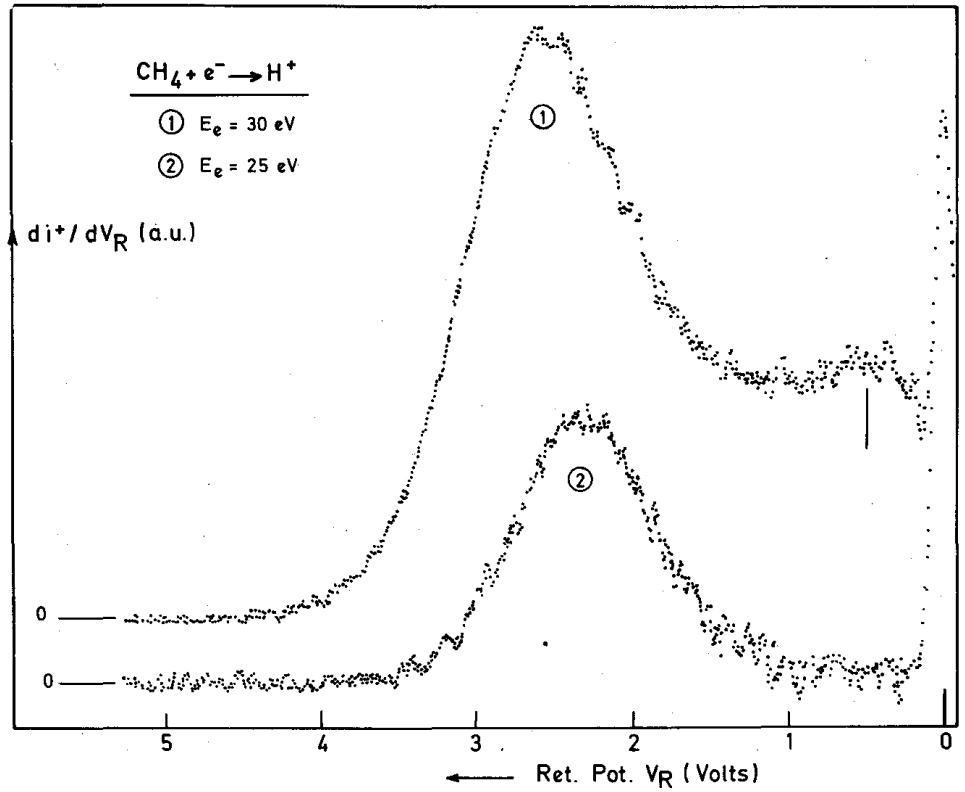

\subsection{Process (5)}

The last onset in the electroionization efficiency curve of $\mathrm{H}^{+}$for the retarding potential setting $V_{\mathrm{R}}=0 \mathrm{~V}$ is measured at $29.4 \pm 0.3 \mathrm{eV}$. As shown in fig. 3, the appearance energy is linearly dependent upon the kinetic energy in the energy range of $0-0.6 \mathrm{eV}$. These protons contribute to an intensity increase of the thermal and nearly thermal ions in the kinetic energy distribution. 
Considering the low scattering of the average values of the threshold energies, a least-squares fitted straight line has been attempted. This line extrapolates to $29.6 \mathrm{eV}$ for $\mathrm{KE}\left(\mathrm{H}^{+}\right)=0 \mathrm{eV}$ and has a slope of 0.3 .

For low energetic protons, Appell [2] measured an appearance energy of about $31 \mathrm{eV}$ : no interpretation is proposed. Schiavone et al. [5] do not observe low-energy high-Rydberg $\mathrm{H}$ atoms at this energy.

The energy range covered by process (5) and the following protons producing dissociations overlap the second electron band ascribed by van der Wiel et al. [4] to a doubly excited configuration of $\mathrm{CH}_{4}^{+}$. The adiabatic and vertical energies are estimated at $28.5 \mathrm{eV}$ and $31 \mathrm{eV}$, respectively.

The extrapolated onset energy of $29.6 \pm 0.3 \mathrm{eV}$ determined in the present experiment corresponds fairly well to the energy for the process

$$
\mathrm{CH}_{4}+\mathrm{e}^{-} \rightarrow \mathrm{H}^{+}+2 \mathrm{H}+\mathrm{CH}\left(\mathrm{A}^{2} \Delta\right)+2 \mathrm{e}^{-},
$$

calculated at $30.2 \mathrm{eV}$. The slope of 0.3 could account for the equipartition of the excess kinetic energy on the lost proton and the two hydrogen atoms. The existence of an ionized state of $\mathrm{CH}_{4}$ in the energy range of $30 \mathrm{eV}$ and the absence of low energy high-Rydberg hydrogen atoms in the same energy range would favour a mechanism where the last process proceeds through direct dissociative or predissociative ionization.

However, other mechanisms like processes (13) and (18) in table 2 could not be definitely ruled out.

\subsection{Process (6)}

Well separated from process (5) the next proton producing process extends over an ion energy range of 0.8-2.8 eV. These ions could be responsible for the $0.9 \mathrm{eV}$ maximum observed in the proton energy distribution observed at $50 \mathrm{eV}$ electron energy (see fig. 1).

The kinetic energy-versus-appearance energy diagram shows a straightforward linear dependence (see fig. 3). The least-squares fit applied to the measured onset energies gives a slope of 1.0 and from the extrapolation to zero ion energy an appearance energy of $31.9 \mathrm{eV}$ is obtained.

The extrapolated value of $31.9 \mathrm{eV}$ for the appearance energy agrees well with the thermochemical onset calculated for the mechanism

$$
\mathrm{CH}_{4}+\mathrm{e}^{-} \rightarrow \mathrm{H}^{+}+3 \mathrm{H}+\mathrm{C}\left({ }^{1} \mathrm{D}\right)+2 \mathrm{e}^{-}
$$

at $32.0 \mathrm{eV}$. In this one-step process, however, the theoretical slope of the straight line in the kinetic energyversus-appearance energy diagram has to account for the loss of one proton and three hydrogen atoms. Assuming the equipartition of the excess translational energy on the four lightest particles, a slope of $1 / 4 \times 12 / 13=0.19$ is obtained. This value has to be compared with 1.0 determined from the experimental data.

To account for both the experimental slope and the extrapolated value of the appearance energy, a twostep mechanism has to be invoked for the appearance of $\mathrm{H}^{+}$, i.e.

$$
\begin{aligned}
\mathrm{CH}_{4}+\mathrm{e}^{-} \rightarrow & \mathrm{CH}^{+}\left(\mathrm{C}^{1} \Sigma^{+} \text {and } / \text { or }{ }^{1} \Pi\right)+3 \mathrm{H}+2 \mathrm{e}^{-} \\
& \longrightarrow \mathrm{C}\left({ }^{1} \mathrm{D}\right)+\mathrm{H}^{+} .
\end{aligned}
$$

The proton being produced by process (b), the slope of the curve giving the excess translational energy carried by $\mathrm{H}^{+}$, as a function of the appearance energy, is given by the ratio $12 / 13=0.92$. The thermochemical threshold for process (a) is calculated at $24.36 \mathrm{eV}$, when implicitly assuming the formation of $\mathrm{CH}^{+}$without excess internal and translational energy. This value has been fitted on the potential energy diagram of $\mathrm{CH}^{+}$as calculated by Lorquet et al. [12] and partially reproduced in fig. 6. The experimental data and the proton energy distribution have been introduced in this diagram, where the energy of $31.9 \mathrm{eV}$ corresponds fairly well to the dissociation process (b) and the kinetic energy distribution observed on $\mathrm{H}^{+}$could arise from a transition to the continuum of the $\mathrm{C}^{1} \Sigma^{+}$and/or the ${ }^{1} \Pi$ state converging both to $32.0 \mathrm{eV}$. 
Fig. 6. Potential energy diagram of $\mathrm{CH}^{+}$taken from ref. [12]. For the sake of clarity only those curves used in the discussion (see text) have been reproduced in this figure.

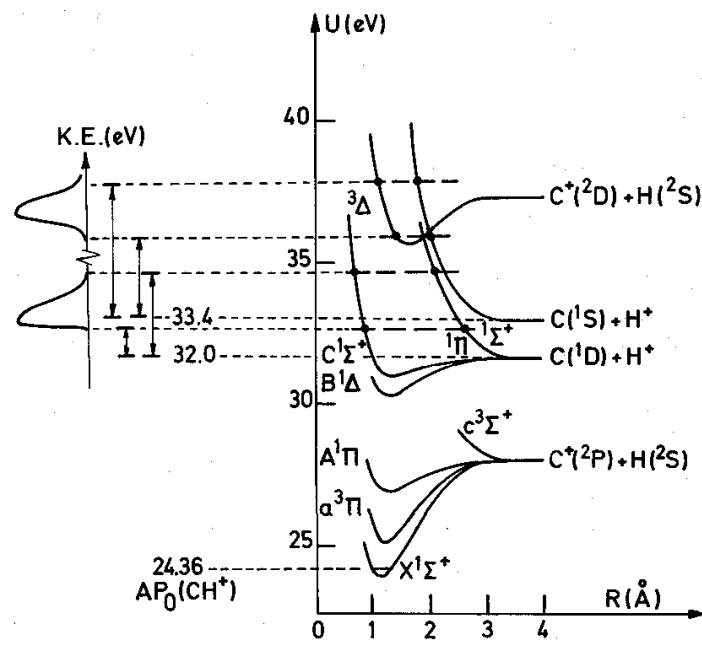

\subsection{Process (7)}

In the proton energy range of 3.0-5.0 eV the data show a linear dependence upon the appearance energy and lead to a least-square-fitted straight line with a slope of 1.1 and an appearance energy of $33.4 \mathrm{eV}$ as extrapolated to zero kinetic energy. The obtained slope is close to the theoretical one that one would obtain under the unlikely assumption that the total excess kinetic energy be carried away by the proton, leaving the three $\mathrm{H}$ atoms at rest.

The dissociation limit, i.e. $33.4 \mathrm{eV}$ obtained by extrapolation of the least-square-fitted straight line, is in good agreement with the onset calculated for the process

$$
\mathrm{CH}_{4}+\mathrm{e}^{-} \rightarrow \mathrm{H}^{+}+3 \mathrm{H}+\mathrm{C}\left({ }^{1} \mathrm{~S}\right)+2 \mathrm{e}^{-} \text {, }
$$

which is at $33.4 \mathrm{eV}$. As in the foregoing section, in this process we should have to observe a slope of 0.19 the excess translational energy being shared by all the particles involved in the dissociation. The observed slope of 1.1 could only be interpreted by the two-step mechanism

$$
\begin{gathered}
\mathrm{CH}_{4}+\mathrm{e}^{-} \rightarrow \mathrm{CH}^{+}\left({ }^{3} \Delta \text { and } / \text { or }{ }^{1} \Sigma^{+}\right)+3 \mathrm{H}+2 \mathrm{e}^{-} \\
\stackrel{\rightarrow C}{ }\left({ }^{1} \mathrm{~S}\right)+\mathrm{H}^{+},
\end{gathered}
$$

for which the KE-versus-AP straight line would have a slope of 0.92 and the thermochemical threshold is at 33.4 $\mathrm{eV}$.

The proton energy distribution as well as the experimental data have been introduced in the potential energy diagram reproduced in fig. 6. The formation of protons with $3-5 \mathrm{eV}$ kinetic energy could be ascribed to transitions to the ${ }^{3} \Delta$ state predissociated by the ${ }^{1} \Sigma^{+}$state converging to the $\mathrm{H}^{+}+\mathrm{C}\left({ }^{1} \mathrm{~S}\right)$ dissociation limit. The higher energetic protons could be produced by direct transitions to one or both continua of the ${ }^{3} \Delta$ or ${ }^{1} \Sigma^{+}$states.

The possible formation of the proton through transitions to unstable doubly ionized states of $\mathrm{CH}_{4}$, such as processes (24) and (26) listed in table 2 could probably be discarded because double ionization starts around $40 \mathrm{eV}[13]$.

\section{Conclusions}

The careful investigation of the proton formation through dissociative ionization of methane (and methane- $d_{4}$ in ref. [1]) shows that (i) at electron energies in the vicinity of the first threshold only dissociative autoionization phenomena are involved and (ii) in the energy range of $26-35 \mathrm{eV}$ predissociation, probably 
Published in : Chemical Physics, iss.49, (1980), vol. 49, pp.173-180

Status: Postprint (Author's version)

associated with doubly excited states of $\mathrm{CH}_{4}^{+}$, give rise to protons. The interpretation of some of the experimental data gathered in the present work would require the appearance of $\mathrm{H}^{+}$from the dissociation of one intermediate fragment ion $\left(\mathrm{CH}^{+}\right)$.

\section{Acknowledgement}

We thank the Belgian "Fonds National de la Recherche Scientifique" and the "Fonds de la Recherche Fondamentale Collective" for financial support.

\section{References}

[1] R. Locht, J. L. Olivier and J. Momigny, Chem. Phys. 43 (1979) 425.

[2] J. Appell, These d'Etat, Université Paris-Sud, France (1972).

[3] C. Backx, G.R. Wight, R.R. Tol and M.J. van der Wiel, J. Phys. B8 (1975) 3007.

[4] M. J. van der Wiel, W. Stoll, A. Hamnett and C.E. Brion, Chem. Phys. Letters 37 (1976) 240.

[5] J. A. Schiavone, D. E. Donohue and R.S. Freund, J.Chem. Phys. 67 (1977) 759.

[6] T. G. Finn, B. L. Carnahan, W. C. Wells and E.C. Zipf, J. Chem. Phys. 63 (1975) 1596.

[7] H. Oertel, Diplomarbeit, Universität Hamburg, Germany (1977).

[8] B. de B. Darwent, Bond Dissociation Energies in Simple Molecules, NSRDS-NBS 31 (1970).

[9] C.E. Moore, Atomic energy levels, Circ. NBS 467 (1949).

[10] B. Rosen, Selected constants. Spectroscopic data relative to diatomic molecules (Pergamon Press, New York, 1970).

[11] G. Herzberg, Molecular spectra and molecular structure,Vol. 3 (Van Nostrand, Princeton, 1967).

[12] A. J. Lorquet, J.C. Lorquet, H. Wankenne and J. Momigny, J. Chem. Phys. 55 (1971) 4053.

[13] C. Backx, M. J. van der Wiel, J. Phys. B8 (1975) 3020.

[14] J.C. Leclerc, C. Guissard-Galloy, Bull. Soc. Chim. Belg. 83 (1974) 327.

[15] J. Dyke, N. Jonathan, E. Lee and A. Morris, J. Chem. Soc. Faraday Trans. II 72 (1976) 1385. 